\title{
Results of treatment of displaced supracondylar humeral fractures in children by percutaneous lateral cross-wiring technique
}

\author{
Wael A. El-Adl · Mohammed A. El-Said • \\ George W. Boghdady $\cdot$ Al-Sayed M. Ali
}

Received: 17 December 2007 / Accepted: 19 January 2008/Published online: 22 February 2008

(C) Springer-Verlag 2008

\begin{abstract}
Seventy children with displaced type II and III supracondylar fractures of the humerus were managed with percutaneous lateral cross-wiring technique from January 2006 to January 2007. There were 54 boys and 16 girls with a mean age of $6.1 \pm 3.07$ years. All patients were operated within $24 \mathrm{~h}$ after trauma using the Dorgans percutaneous lateral cross-wiring technique. Patients were followed up for a mean period of $6.1 \pm 2.6$ months and assessed both radiologically for union; and functionally and cosmetically according to Flynn's criteria. All patients achieved solid union. Functionally, all patients achieved satisfactory results, while cosmetically, $91.4 \%$ of patients had satisfactory results and $8.6 \%$ had unsatisfactory results. The most frequently occurring complications were minor pin tract infection in six patients, deep infection in two patients, and 32 patients suffered excessive granulation tissue formation mostly around the proximal pin. There was no iatrogenic neurological injury either for the ulnar or for the radial nerves. The obtained results and minor complications reported signify this technique as a viable treatment method for displaced type II and III supracondylar fractures in children.
\end{abstract}

Keywords Humeral supracondylar fracture . Percutaneous pinning - Lateral cross-wiring technique

W. A. El-Adl · M. A. El-Said · G. W. Boghdady ( $₫)$.

A.-S. M. Ali

Orthopaedic Department, Faculty of Medicine,

Mansoura University, P.O. Box 2, Mansoura, Egypt

e-mail: georgewadeed@gmail.com

W. A. El-Adl

e-mail: waelalimaher@hotmail.com

\section{Introduction}

Supracondylar fractures of the humerus are the most common type of elbow fractures in children and adolescents accounting for $50-70 \%$ of all elbow fractures [1]. There has been an argument concerning the ideal method of treatment of displaced supracondylar humeral fractures. Recommended treatment modalities vary from no reduction and immobilisation to open reduction and internal fixation. Because of the difficulty in maintaining an adequate reduction with cast immobilisation, stabilization of the reduced fractures with pins placed percutaneously has become the universally accepted method of treatment [2].

There have been numerous variations of recommended pinning techniques. Swenson [3], Flynn et al. [4], and Nacht et al. [5], using two pins, inserted medially and laterally through the medial and lateral epicondyles. The risk of iatrogenic ulnar nerve injury is always a concern during insertion of the medial pin with a reported incidence of 2-8\% [6-10]. Arino et al. [11] recommended inserting the two wires through the lateral epicondyles to avoid ulnar nerve injury. Biomechanically, fixation provided by the two lateral pins is less secure, as it may allow rotation of the fracture, with the medial column rotating posteriorly. It was found that the torque required to produce $10^{\circ}$ of rotation is $37 \%$ less with the use of two lateral parallel pins than with the use of medial and lateral pins $[4,12]$. It has been argued that insertion of two lateral cross-pins will provide a biomechanically stable fixation with avoiding the risk of ulnar nerve injury [13]. The aim of the present study is to evaluate the results of percutaneous lateral cross-wiring technique in treatment of unstable or irreducible type II and III supracondylar humeral fractures in children. 


\section{Materials and methods}

Between January 2006 and January 2007, 70 children with unstable displaced or irreducible type II and type III supracondylar humeral fractures were managed with the percutaneous lateral cross-wiring technique in the Orthopaedic Department, Mansoura Faculty of Medicine, Egypt. There were 54 boys $(77.1 \%)$ and 16 girls $(22.9 \%)$. Their age ranged from 1 to 13 years with a mean of $6.1 \pm 3.07$ years. There were 36 patients $(51.4 \%)$ below the age of 6 years and 34 patients $(48.6 \%)$ above that age. Both right and left sides were nearly equally affected. Most of the injuries were due to falling during running (60\%). On presentation, patients were fully assessed clinically both generally and locally. Special attention was paid to peripheral circulation and neurological status.

Closed fractures were encountered in 64 patients $(91.4 \%)$, while open fractures were found in six patients $(8.6 \%)$, of which five had grade I open fracture and one had grade IIIc open fracture (associated with brachial artery injury). Radial pulse was absent at first presentation in four patients, and radial nerve injury was documented in six patients. All the patients suffered extension type fractures. Fractures were classified according to Gartland's classification [14]. Ten patients $(14.3 \%)$ were not manipulated before operation, 50 patients $(71.4 \%)$ were manipulated once, and ten patients $(14.3 \%)$ were manipulated twice.

All patients were operated on within $24 \mathrm{~h}$ after trauma, utilizing the "Dorgan's" percutaneous lateral cross-wiring technique [13], as shown in Fig. 1. Closed reduction of the fractures by traction and manipulations was done in all patients except for the six patients with open fractures in whom open reduction was done through a lateral approach.

Immediate postoperative neurological assessment for median, ulnar, and radial nerves was performed. Period of hospitalisation was 1-2 days. Patients were followed up at 1 week for radiological confirmation of maintenance of
Fig. 1 a The point of entry should be in the metaphyseal part " 1 " and not in the diaphyseal part "2" of the humerus. b The second wire may skid down the lateral cortex during introduction. $\mathbf{c}$ The wire is directed at right angles to the cortex until penetrated, pulling back, and then adjusting the trajectory. d The second wire is introduced through the lateral cortex, proximal to the fracture line, and is driven across the fracture into the medial condyle. Wires must cross above the fracture line
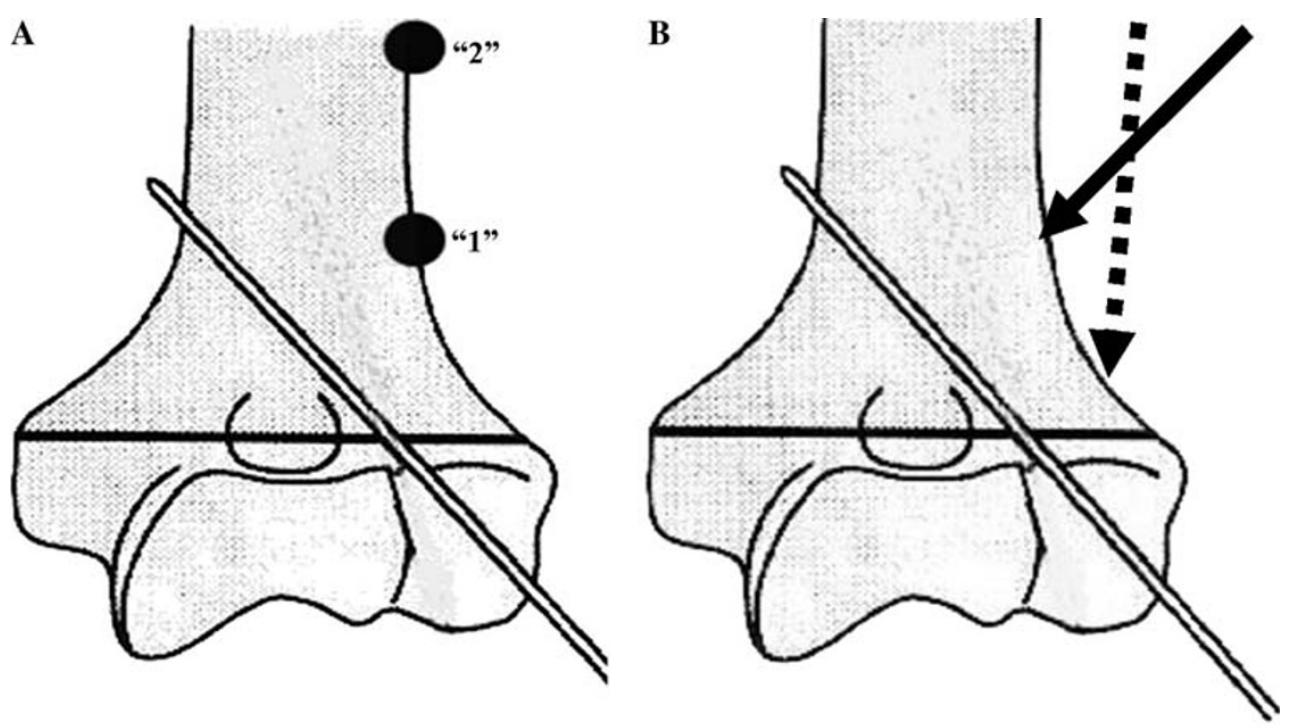

C

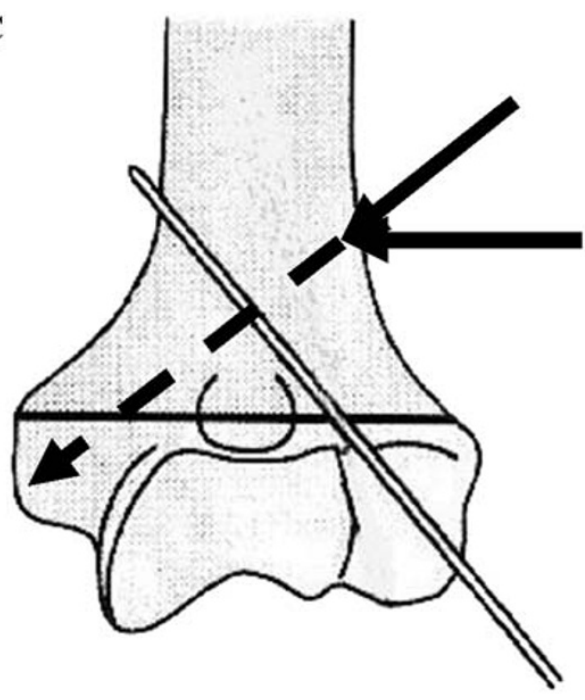

D

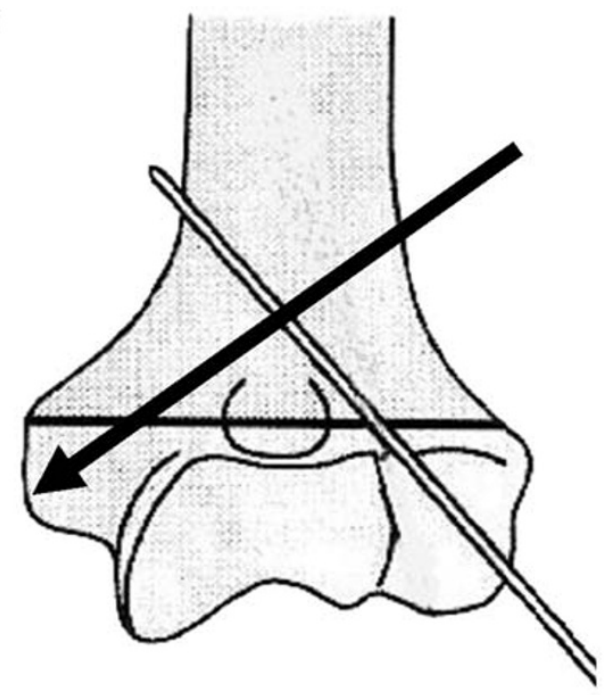


Table 1 Flynn's criteria for cosmetic and functional assessment of results

\begin{tabular}{lll}
\hline Result rating & $\begin{array}{l}\text { Cosmetic factor } \\
\text { Carrying angle loss }\end{array}$ & $\begin{array}{l}\text { Functional factor } \\
\text { Loss of motion }\end{array}$ \\
\hline Excellent & $0-5$ & $0-5$ \\
Good & $6-10$ & $6-10$ \\
Fair & $11-15$ & $11-15$ \\
Poor & $>15$ & $>15$ \\
\hline
\end{tabular}

reduction, at 4 weeks to remove the $\mathrm{K}$ wires and start movement, monthly for a minimum of 4 months, and then with a mean period of $6.1 \pm 2.6$ months. At the last follow-up, patients were assessed both radiologically for union and functionally according to Flynn's criteria [5] as shown in Table 1. Internal rotation deformity was measured by the method described by Yamamoto et al. [15], with the patient bending slightly forward. The patient's arm is held at the side with the elbow in flexed at $90^{\circ}$ and the shoulder held in maximum extension. In this position, maximum internal rotation strain is applied to the patient's arm. The angle formed between the horizontal plane of the back and the midline of the forearm represents the internal rotation deformity.

The results were tabulated as frequency distribution for different qualitative values. Using the standard version of the SPSS program (release 10), the arithmetic mean and standard deviation were collected for quantitative variables. Comparison between those with satisfactory outcome and those with unsatisfactory outcome was done using $\chi^{2}$ (chi square) test of significance.

\section{Results}

Functionally, all patients had satisfactory results; 60 patients had excellent results (85.7\%) (Figs. 2, 3, 4, 5), eight patients had good results (11.4\%) (Fig. 6, 7), two patients had fair results $(2.9 \%)$, and no patient had poor result. Cosmetically, $91.4 \%$ had satisfactory results and $8.6 \%$ had unsatisfactory results; 54 patients had excellent results $(77.1 \%)$, eight patients had good results (11.4\%), two patients had fair results $(2.9 \%)$ (Fig. 6, 7), and six patients had poor results $(8.6 \%)$.

There was no statistical difference in the functional results between boys and girls; all patients in both groups had satisfactory results, while girls yielded better cosmetic results than boys, but the difference was statistically insignificant. Also functionally, there was no statistical difference in the results between patients below 6 years of age and those above 6 years; all patients had satisfactory results. All patients had cosmetically satisfactory results except for $5.9 \%$ of patients above the age of 6 years, with statistically insignificant difference between the two age groups $\left(\chi^{2}=0.373 / P>0.05\right)$.

Regarding the type of the fracture and degree of displacement, there were 18 patients with Garteland type II fractures and 52 patients with type III fractures; all of them had satisfactory functional and cosmetic results except for $11.5 \%$ of patients with type III fractures who had unsatisfactory statistically insignificant cosmetic results $\left(\chi^{2}=0.309 / P>0.05\right)$.

Complications were represented in the present study in the form of six patients $(8.6 \%)$ who had minor pin-site infection that resolved after K-wire removal and oral antibiotics; two patients (2.9\%) with grade 1 open fracture developed bone infection at the site of entry of the proximal pin in the lateral cortex; excessive granulation tissue around a wire was noted in 32 patients (45\%) especially around the proximal wire than the distal wire; and cubitus varus deformity, which was related to the quality of the reduction, was noted in six patients $(8.6 \%)$, whose reduction quality was unsatisfactory. All these six patients had Gartland type III fractures with two failed trials of preoperative manipulations. Internal rotation angle was measured according to Yamamoto test [15] in these six patients and planned for later corrective osteotomis.
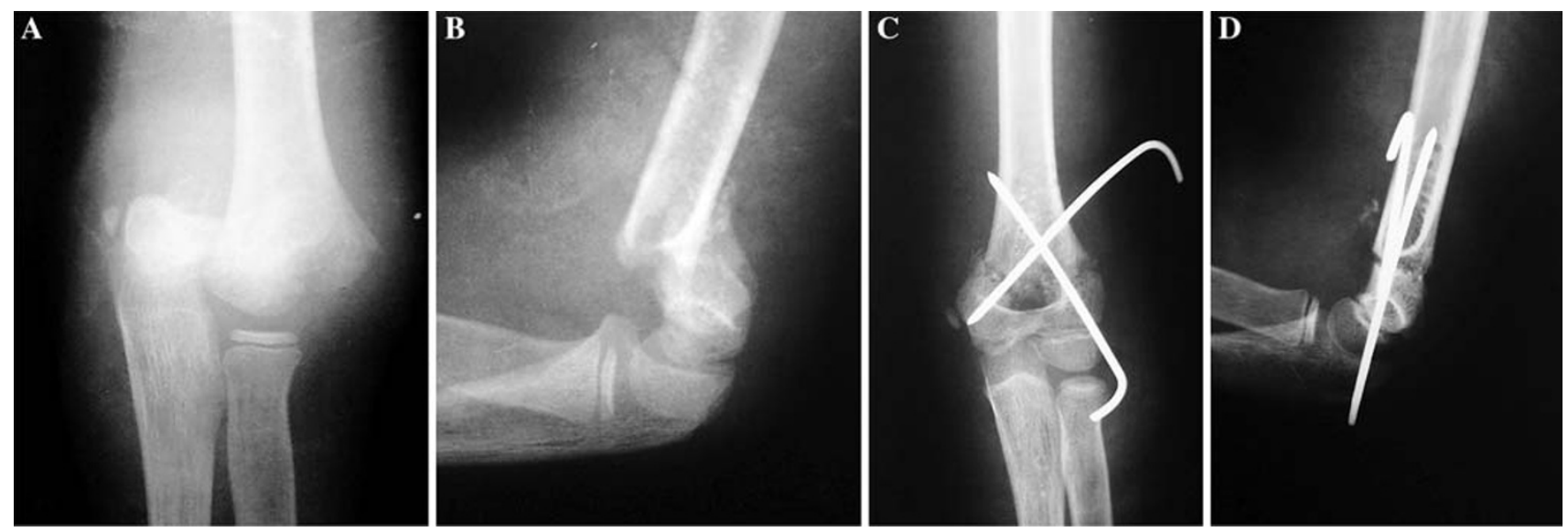

Fig. 2 The preoperative plain X-rays (a, b) of 13-year-old boy with type II displaced supracondylar fracture of the right humerus, fixed with the lateral cross-wiring technique $(\mathbf{c}, \mathbf{d})$ 


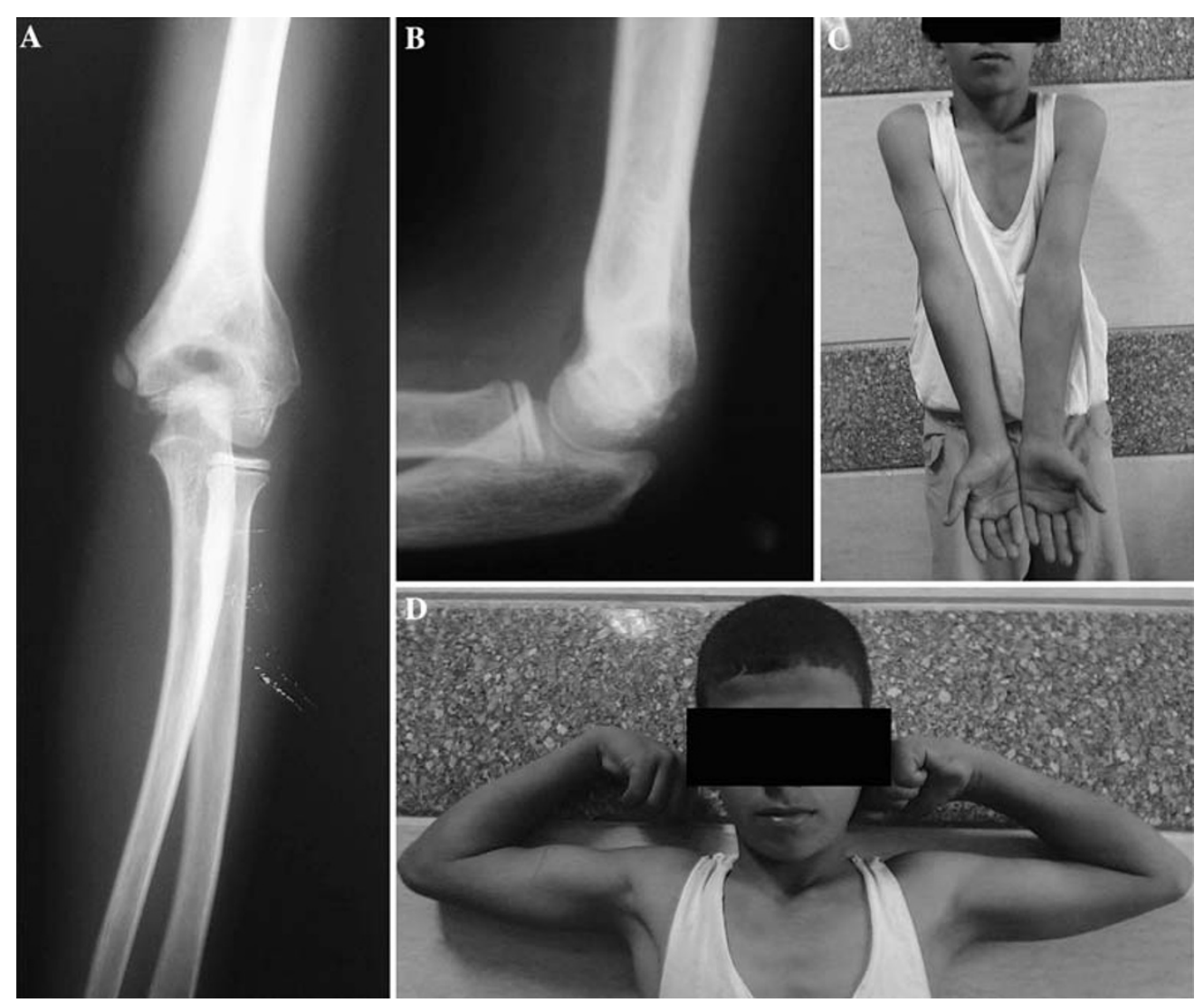

Fig. 3 After 8 months of follow-up both radiologically $(\mathbf{a}, \mathbf{b})$ and functionally $(\mathbf{c}, \mathbf{d})$
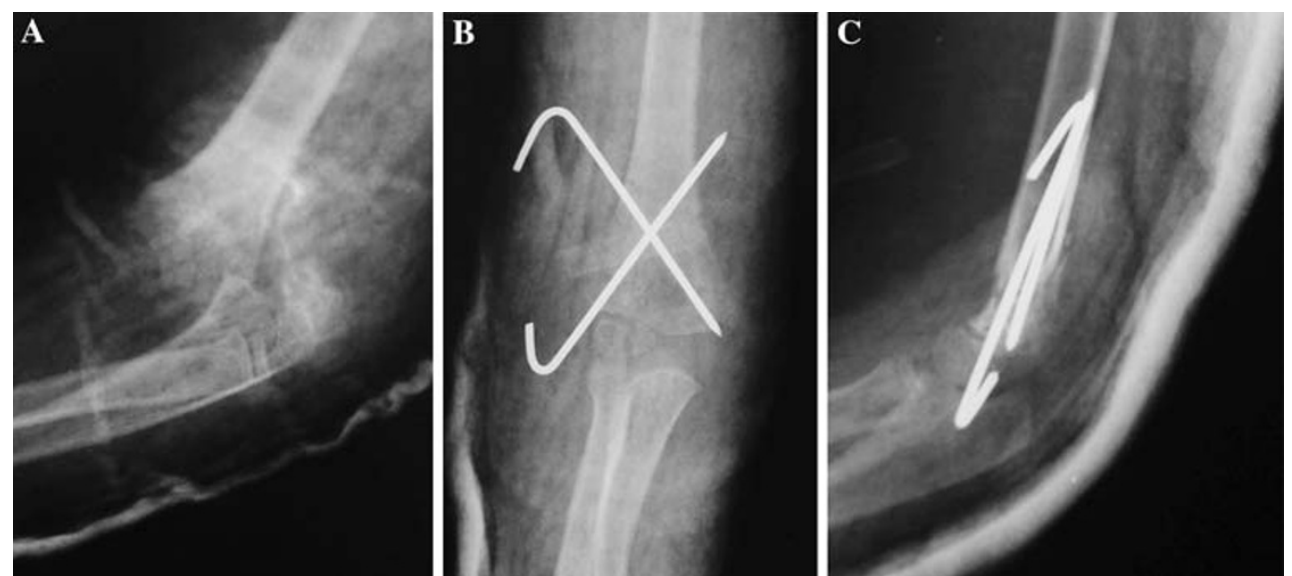

Fig. 4 The preoperative plain X-rays (a) of 5-year-old girl with type III open grade IIIc (with complete injury of the brachial artery) displaced supracondylar fracture of the right humerus, fixed with the lateral cross-wiring technique $(\mathbf{b}, \mathbf{c})$

\section{Discussion}

Supracondylar fractures of the humerus are the commonest types of elbow fractures in children and adolescents accounting for $50-70 \%$ of all elbow fractures and are seen most frequently in children between the age of 3 and 10 years [1]. There has been no uniformity of opinion concerning the ideal method of treatment of displaced supracondylar fractures. Several treatment modalities have been recommended including closed reduction and plaster immobilisation [16, 17], open reduction and internal fixation [16, 18-21], traction [16, 18, 22-25], and closed reduction and percutaneous pinning [11, 16, 19, 26].

While closed manipulation and percutaneous Kirschner wire stabilization is the accepted treatment of displaced supracondylar fractures of the humerus in children, there is 

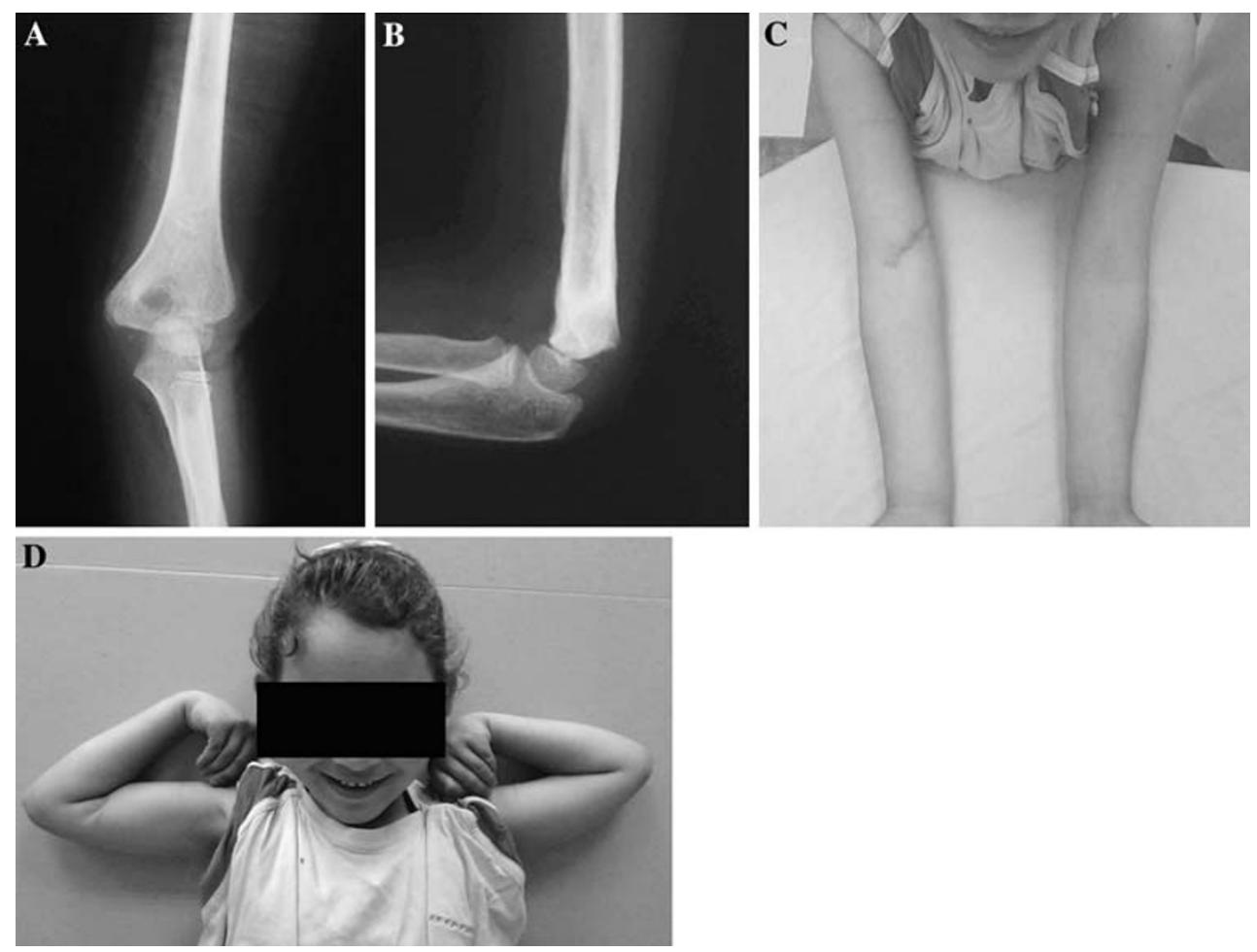

Fig. 5 After 6 months of follow-up both radiologically (a, b) and functionally (c, d)

still argument on the optimal configuration of those Kirschner wires. Danielsson and Pettersson [20] used only one pin and noted a loss of reduction. Swenson [3], Flynn et al. [4], and Nacht et al. [5] have, using two pins, introduced through the medial and lateral epicondyles, respectively. The two-wire cross-fixation is the most commonly used and good results have been reported, but injury of the ulnar nerve when inserting the medial wire has been documented ranging from 2 to $8 \%$ [6-10].

There have been numerous reports of modified fixation techniques to prevent fracture redisplacement and ulnar nerve injury with varying degrees of stability, redisplacement neurological injuries, and functional and cosmetic results $[10,12,27,28]$.

In the present study, we studied the recently introduced Dorgan's percutaneous lateral cross-wiring technique for supracondylar humeral fractures performed solely from the lateral side. While this technique does not include supporting biomechanical data, the crossed-wire configuration obtained by inserting both wires from the lateral side is identical to that obtained via the traditional medial and lateral technique. The ulnar nerve is not at risk, unless the proximally inserted wire is driven through the medial condyle. Theoretically, the radial nerve could be injured during insertion of the more proximal wire. However, the radial nerve is situated anterior to the lateral intermuscular septum at this level and can be avoided by entering the skin a little posterior to the mid-coronal plane.
In Shannon's [13] series (20 patients), all children had a full range of the elbow motion compared with their other (normal) side, and the mean carrying angle of the injured elbow was $15^{\circ}$ (range $10^{\circ}-20^{\circ}$ ). There were no intraoperative complications; of note, there were no ulnar nerve injuries. All complications were related to the Kirschner wires.

In the present study, no median or ulnar nerve injuries were found in any patient. Radial nerve injury was found in six patients $(8.6 \%)$ preoperatively, and in all patients the radial nerve injury recovers within 2 months after injury. In contrast to Cramer et al. [29] and Dormans et al. [30], no iatrogenic nerve injuries were encountered in any of the patients.

Shannon [13] reported on one patient with a minor pinsite infection. While in our study, there were six patients $(6.8 \%)$ with minor pin-site infection that resolved after $\mathrm{K}$-wire removal and oral antibiotics. Also, two patients (2.9\%) developed bone infection at the site of entry of the proximal pin in the lateral cortex with a sinus discharging pus that does not respond to antibiotics given according to the culture taken from the sinus; these patients responded to debridement and curettage of the bone through lateral approach. The relatively increased infection rate in the present study may be attributed to the larger number of patients encountered and to the presence of six patients with open fractures. 

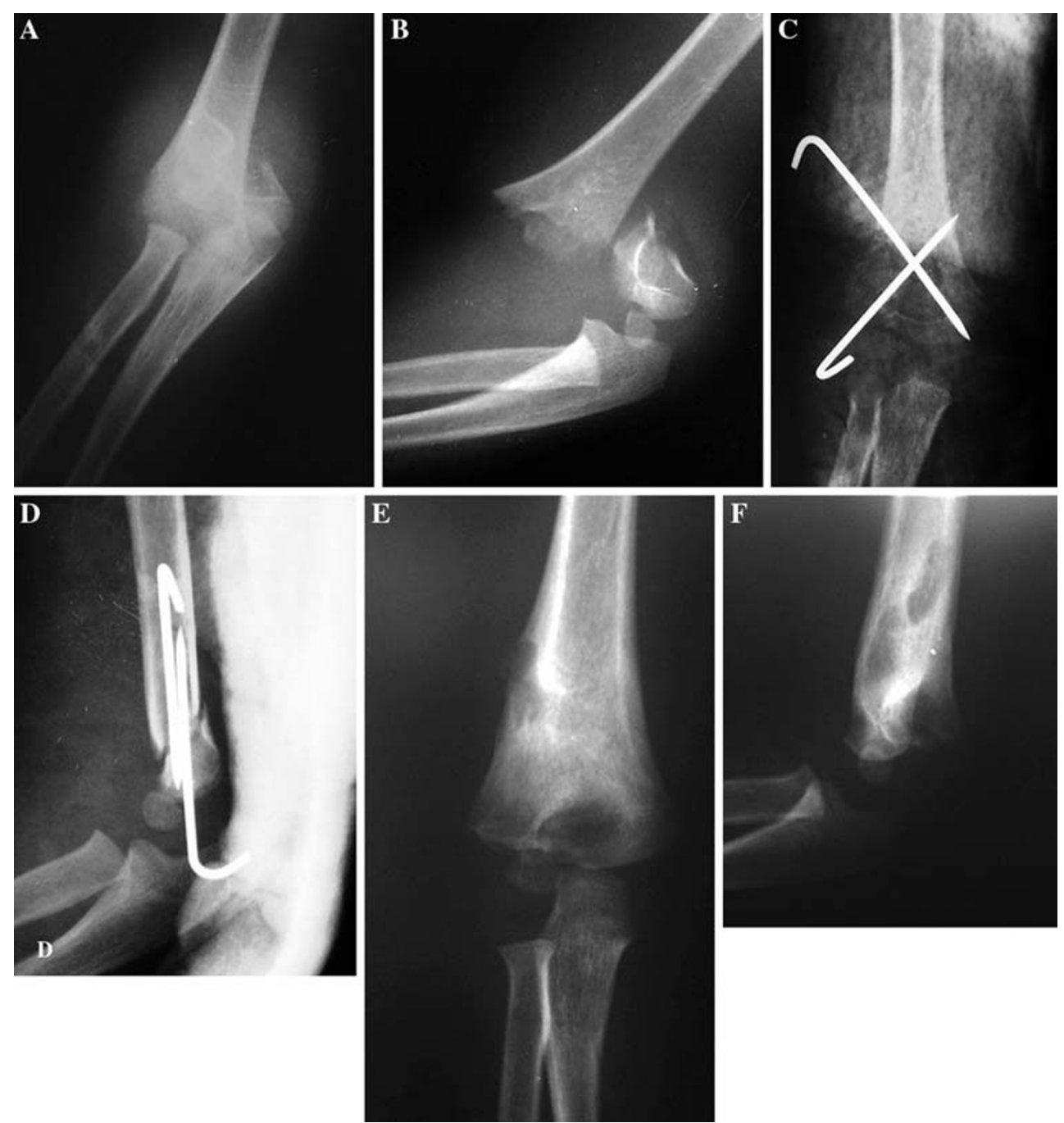

Fig. 6 The preoperative plain X-rays $(\mathbf{a}, \mathbf{b})$ of 3-year-old boy with type III displaced supracondylar fracture of the right humerus, fixed with the lateral cross-wiring technique $(\mathbf{c}, \mathbf{d})$; with deep bone infection $(\mathbf{e}, \mathbf{f})$ that was treated surgically with debridement and bone curettage

Fig. 7 a, b and $\mathbf{c}$ show the radiological and functional results at 8 months
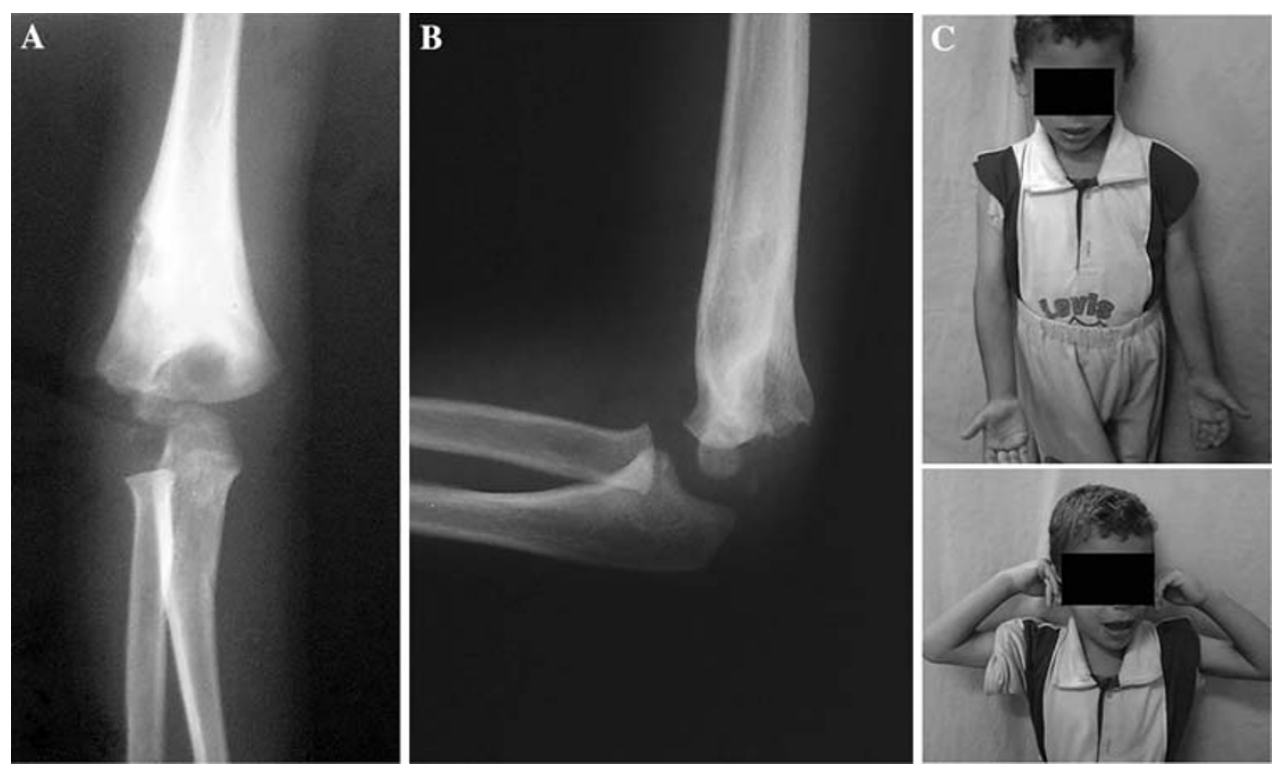
Excessive granulation tissue formation around a wire was noted in 32 patients (45\%), which were managed successfully by curettage, dressing in the outpatient clinic, and oral antibiotics. Most of the patients developed excessive granulation tissue around the proximal wire than the distal wire. These results are comparable with those of Shannon [13], which reported on five patients (40\%) who developed excessive granulation tissue around a wire.

In contrast to results obtained by Shannon [13], cubitus varus deformity was noted in six patients $(8.6 \%)$ in the present study. This was related to unsatisfactory reduction of the fracture before pinning. The six patients suffered posteromedially displaced type III fracture with two failed trials of reduction. No revision surgeries were done. A fear of possible increased incidence of myositis ossificans prevented further closed or open reduction trials, and reductions were rated as accepted.

\section{Conclusion}

Within the obtained results, complications, and limitations of the present study, the lateral cross-wiring technique is a viable solution for percutaneous fixation of displaced supracondylar fractures in children. It provides good fracture stability, good union rate, and acceptable complication rate with minimal risk of iatrogenic nerve injuries. A further long-term study will be conducted by the authors on all patients to assess late complications, e.g., fish tail deformities with a minimum of 2 years of follow-up.

\section{References}

1. Hanlon CR, Estes WL (1954) Fractures in children: a statistical analysis. J Bone Joint Surg Am 87:312

2. McIntyre W (1996) Supracondylar fractures of the humerus. In: Letts RM (ed) Management of pediatric fractures, vol 11. Churchill Livingstone, New York. pp 167-198

3. Swenson AL (1948) Treatment of supracondylar fractures of the humerus by Kirschner wire trans-fixation. J Bone Joint Surg Am 30:993-997

4. Flynn JC, Mathews JG, Benoit RL (1974) Blind pinning of displaced supracondylar fractures of the humerus in children. J Bone Joint Surg Am 56:263-273

5. Nacht JL, Eker ML, Chug SMK et al (1983) Supracondylar fracture of the humerus in children treated by closed reduction and percutaneous pinning. Clin Orthop Relat Res 177:203

6. Brown IC, Zinar DM (1995) Traumatic and iatrogenic neurological complication after supracondylar fractures of the humerus in children. J Pediatr Orthop 15:440-443

7. Campbell C, Waters P, Emans J et al (1995) Neurovascular injury and displacement in type III supracondylar humerus fractures. J Pediatr Orthop 25:47

8. Royce RO, Dutkowsky JP, Kasser JP et al (1992) Neurological complication after K-wire fixation of supracondylar fractures of the humerus in children. J Pediatr Orthop 11:191-194
9. Skaggs DL, Hale JM, Bassett J et al (2001) Operative treatment of supracondylar fractures of the humerus in children. The consequences of pin placement. J Bone Joint Surg Am 83A:735-740

10. Topping RE, Blanco JS, Davis T (1995) Clinical evaluation of crossed pin versus lateral pin fixation in displaced supracondylar fractures of the humerus. J Pediatr Orthop 15:435-439

11. Arino VC, Lluch EE, Ramirez AM et al (1997) Percutaneous fixation of supracondylar fractures of the humerus in children. J Bone Joint Surg Am 59:914

12. Zionts LE, Mckellop HA, Hathaway R (1994) Torsional strength of pin configuration Used to fix supracondylar fractures of the humerus in children. J Bone Joint Surg Am 76:253-256

13. Shannon FJ (2004) Dorgan's percutaneous lateral cross wiring of supracondylar fractures of the humerus in children. J Pediatr Orthop 24:376-379

14. Hotchkiss NR, Green PD (1991) Fracture and dislocation of the elbow. In: Rockwood CA, Green DP, Bucholz RW (eds) Fractures in adult, vol 1, 3rd edn. JB Lippincott Company, Philadelphia, pp 739-827

15. Yamamoto I, Ishii S, Usui M, Ogino T, Kuneda K (1985) Cubitus varus deformity following supracondylar fracture of the humerus: a method for measuring rotational deformity. Clin Orthop Relat Res 201:179-185

16. Celiker O, Pestilci FI, Tuzuner M (1990) Supracondylar fractures of the humerus in children: analysis of the results in 142 patients. J Orthop Trauma 4:265

17. Eid AM (1978) Reduction of displaced supracondylar fractures of the humerus in children by manipulation in flexion. Acta Orthop Scand 49:391

18. Pirone AM, Graham HK, Krajbich JI (1988) Management of displaced extension type Supracondylar fractures of the humerus in children. J Bone Joint Surg Am 70:641-650

19. Wilkins KE (1990) The operative management of supracondylar fractures. Orthop Clin North Am 21:269

20. Danielsson L, Pettersson H (1980) Open reduction and pin fixation of severely displaced supracondylar fractures of the humerus in children. Acta Orthop Scand 15:249

21. Hart GM, Wilson DW, Arden GP (1977) The operative management of the difficult supracondylar fracture of the humerus in the child. Injury Br J Accid Surg 9:30

22. Millis MB, Singer IJ, Hall JE (1984) Supracondylar fracture of the humerus in children: further experience with a study in orthopedic decision-making. Clin Orthop Relat Res 188:90

23. Sutton WR, Greene WB, Georgopoulos G, Dameron TB Jr (1992) Displaced supracondylar humeral fractures. Clin Orthop Relat Res 278:81

24. Kramhoft M, Keller IL, Solgaard S (1987) Displaced supracondylar fractures of the humerus in children. Clin Orthop Relat Res 221:215

25. Alburger PO, Weidner PL, Betz R (1992) Supracondylar fractures of the humerus in children. J Pediatr Orthop 12:12

26. Aronson DD, Prager PI (1987) Supracondylar fractures of the humerus in children: a modified technique for closed pinning. Clin Orthop Relat Res 219:174-184

27. Mubarak SJ, Davids JR (1994) Closed reduction and percutaneous pinning of supracondylar fractures of the distal humerus in the child. Master techniques in orthopedic surgery. In: Morrey BF (ed) The Elbow. Raven Press, New York, pp 37-51

28. Lee SS, Mahar AT, Miesen D et al (2002) Displaced pediatric supracondylar humerus fractures: biomechanical analysis of percutaneous pinning techniques. J Pediatr Orthop 22:440-443

29. Cramer KE, DeVito DP, Green NE (1992) Comparison of closed reduction and percutaneous pinning versus open reduction and percutaneous pinning in displaced supracondylar fractures of the humerus in children. J Orthop Trauma 6:407-412

30. Dormans JP, Squillante R, Sharf H (1995) Acute neurovascular complications with supracondylar humerus fractures in children. J Hand Surg (Am) 20:1-4 